\title{
Moderate Intravenous Sedation for First Trimester Surgical Abortion: A Comparison of Adverse Outcomes Between Obese and Normal Weight Women
}

\section{Citation}

Horwitz, Gillian. 2018. Moderate Intravenous Sedation for First Trimester Surgical Abortion: A Comparison of Adverse Outcomes Between Obese and Normal Weight Women. Doctoral dissertation, Harvard Medical School.

\section{Permanent link}

http://nrs.harvard.edu/urn-3:HUL.InstRepos:41973517

\section{Terms of Use}

This article was downloaded from Harvard University's DASH repository, and is made available under the terms and conditions applicable to Other Posted Material, as set forth at http:// nrs.harvard.edu/urn-3:HUL.InstRepos:dash.current.terms-of-use\#LAA

\section{Share Your Story}

The Harvard community has made this article openly available.

Please share how this access benefits you. Submit a story.

\section{Accessibility}


Moderate intravenous sedation for first trimester surgical abortion: A comparison of adverse outcomes between obese and normal weight women

Gillian Horwitz, BS ${ }^{\mathrm{a}}$; Danielle Roncari, MD MPH ${ }^{\mathrm{b}, \mathrm{c}}$; Kari Braaten, MD MPH ${ }^{\mathrm{a}, \mathrm{b}, \mathrm{d}}$; Rie Maurer, $\mathrm{MA}^{\mathrm{d}}$; Jennifer Fortin, MPH ${ }^{\mathrm{b}}$; Alisa B. Goldberg, MD MPH ${ }^{\mathrm{a}, \mathrm{b}, \mathrm{d}}$

${ }^{\mathrm{a}}$ Harvard Medical School, 25 Shattuck Street, Boston, MA, USA 02115; ${ }^{\mathrm{b}}$ Planned Parenthood League of Massachusetts, 1055 Commonwealth Avenue, Boston, MA, USA 02215; ' Tufts Medical Center, 800 Washington Street, Boston, MA, USA 02111; ' Brigham and Women's Hospital, 75 Francis Street, Boston, MA, USA 02115

Corresponding Author:

Alisa Goldberg, MD, MPH Associate Professor, Obstetrics, Gynecology and Repro. Bio. Harvard Medical School Director, Division of Family Planning Brigham and Women's Hospital Vice President, Clinical Research and Training Planned Parenthood League of Massachusetts 1055 Commonwealth Ave. Boston, MA 02215 Tel: (617) 616-1628, email: agoldberg@pplm.org

Sponsor:

Society of Family Planning Research Fund (SFPRF) Harvard Medical School Center for Primary Care Harvard Medical School Scholars in Medicine Program

Disclosures:

The authors have no conflicts of interest. The findings and conclusions expressed in this article are those of the authors and do not necessarily reflect the views of Planned Parenthood Federation of America, Inc.

Presented at:

Oral Presentation, North American Forum on Family Planning, Denver, CO, Nov. 5, 2016

\section{Word Counts:}

Abstract: 230

Manuscript text: 3,026 
47 Abstract

48 Objective: To determine if obese women experience increased rates of adverse outcomes with

49 moderate intravenous sedation during first trimester surgical abortion compared to normal

50 weight women.

51 Study Design: We performed a retrospective cohort study of all first trimester surgical abortions

52 with moderate intravenous sedation at an outpatient facility between September 2010 and June

53 2015. The primary outcome was supplemental oxygen administration. Secondary outcomes

54 included reversal agent administration, anesthesia-related adverse events, and intraoperative

55 lowest level of consciousness (LLOC). We compared three obesity groups [I (Body Mass Index,

$56 \mathrm{BMI}=30-34.9)$, II $(\mathrm{BMI}=35-39.9)$, and III $(\mathrm{BMI} \geq 40)]$ to normal weight women $(\mathrm{BMI}<25)$. We

57 exported data from electronic medical records and reviewed adverse outcomes individually.

58 Results: Of 20,381 first trimester surgical abortion procedures, $31(0.15 \%)$ utilized supplemental

59 oxygen, $24(0.12 \%)$ utilized a reversal agent, $40(0.20 \%)$ had a presumed anesthesia-related

60 adverse event and 184 of 19,725 (0.93\%) had a documented low intraoperative LLOC. One

61 patient $(0.005 \%)$ required hospital transfer or hospitalization. Supplemental oxygen

62 administration (obesity versus normal weight: obese I, aOR 0.52, 95\% CI 0.12-2.27; II/III, aOR

$631.51,95 \%$ CI 0.50-4.54), low intraoperative LLOC, and anesthesia-related adverse events were

64 not associated with obesity. The rate of reversal agent administration was lower among obese I,

65 II and III women combined compared to normal weight women (aOR 0.13, 95\% CI 0.02-0.96).

66 Conclusions: Adverse outcomes were rare across all BMI categories with no detectable

67 increased risk among obese women compared to normal weight women. 
68 Keywords: moderate sedation; intravenous sedation; obesity; BMI; surgical abortion; first

69 trimester

70

71 Implications: With appropriate clinical screening, obese women can safely receive moderate

72 intravenous sedation for first trimester surgical abortion in an outpatient clinical setting.

73 Restrictions on moderate intravenous sedation based on BMI alone may be unnecessary. 


\section{Introduction}

Approximately 926,200 abortions were performed in the United States in 2014, with 89\% occurring within the first 12 weeks gestation and $95 \%$ in an outpatient setting $[1,2]$. By age forty-five, half of American women will have an unintended pregnancy with one in three having an abortion [3, 4]. As of 2010, 31.9\% of women between the ages of 20 to 39 in the United States were obese and 55.8\% were obese or overweight [5]. Thus, abortion among overweight or obese women in the United States is common.

Pain management options for surgical abortion include local anesthesia, oral, moderate, or deep sedation, and general anesthesia $[6,7]$. While deep sedation and general anesthesia provide the greatest analgesia, with these options patients are not easily arousable, sometimes require airway support and require monitoring by anesthesia professionals, limiting their availability in the outpatient setting [8]. With moderate intravenous (IV) sedation patients continue to respond purposefully to verbal or tactile stimulation and have better pain control and satisfaction compared to local anesthesia alone or in combination with oral sedation. Moderate

IV sedation can be administered by a wider array of health care professionals and is more commonly available in the outpatient setting, with $40 \%-100 \%$ of first trimester patients receiving IV sedation [6-13].

While there are limited data on the safety of moderate IV sedation for abortion in obese women, some outpatient clinics have restricted this option due to concern about increased risk of adverse events. In 2016, Planned Parenthood Federation of America issued new guidelines prohibiting IV sedation by non-anesthesia professionals in women with a body mass index (BMI) greater than or equal to 45 and recommending special consideration for women with a BMI between 40 and 45. 
This study sought to determine if BMI is a predictor of adverse outcomes with moderate

98 IV sedation during first trimester surgical abortion to elucidate if BMI-based restrictions are

99 warranted.

\section{2. Material and methods}

We conducted a retrospective cohort study of all first trimester surgical abortion

102 procedures performed with moderate IV sedation at Planned Parenthood League of

103 Massachusetts (PPLM) Health Centers in Boston, Springfield, and Worcester between

104 September 1, 2010 and June 1, 2015. We included procedures in which the patient was thirteen

105 weeks and six days or less by ultrasound and received any IV sedation with fentanyl and/or

106 midazolam. We excluded procedures if the patient received local anesthesia alone, was missing

107 BMI data, or had an extreme BMI. We defined extreme BMI as BMI $<15$ or $\mathrm{BMI}>80$ and

108 assumed that these values were erroneous unless the patient had a similar value documented at

109 another appointment. When women had more than one abortion procedure in our cohort, we

110 included the first procedure and excluded all additional procedures. The Institutional Review

111 Board of the Harvard University Faculty of Medicine exempted this research from review.

112 Patients included in our cohort underwent dilation and vacuum aspiration. Prior to any

113 procedure, a triage nurse medically screened all surgical abortion patients. A physician further

114 evaluated any patients with significant medical conditions, including asthma, diabetes,

115 hypertension, seizure disorder, or a history of cardiac or pulmonary disease, to determine

116 eligibility to have a procedure at PPLM. Women were not eligible for surgical abortion if they

117 had any medical condition judged to be so severe or so poorly controlled that the procedure

118 would pose significant risk. There was no specific BMI cut-off for procedural eligibility. If

119 ineligible, women were referred for hospital-based abortion. 
121 eligibility. Physicians did not provide moderate IV sedation to patients with a relevant drug

122 allergy, no escort home, a concerning pulmonary examination, or perceived significant risk with

123 sedation. We screened patients with asthma for disease triggers and severity and did not offer IV

124 sedation if they had been recently hospitalized for asthma or had poorly controlled disease.

125 Physicians did not offer sedation to any patient with wheezes on lung exam that did not clear 126 with several puffs of an inhaler. From 2010 to 2013, PPLM required patients to be NPO. Starting

127 in 2013, patients were still instructed to be NPO, but sedation was permitted in cases of non-

128 adherence at physician discretion. There was no specific BMI cut-off for sedation eligibility.

129 A registered nurse $(\mathrm{RN})$ administered sedation medications in conjunction with the

130 operating physician. Standard initial doses were $100 \mathrm{mcg}$ fentanyl and $2.0 \mathrm{mg}$ midazolam and

131 were sometimes adjusted at the outset based on clinical factors (i.e. starting dose reduced for low

132 body weight), but could not exceed $150 \mathrm{mcg}$ fentanyl and $3.0 \mathrm{mg}$ midazolam. The operating

133 physician, with input from the RN, decided on additional doses to titrate the sedation during the

134 procedure in response to patient pain and anxiety as needed, typically not exceeding $200 \mathrm{mcg}$

135 fentanyl and $4.0 \mathrm{mg}$ midazolam, although there were no limitations placed on maximum total

136 dosing. Doses were administered to provide a level of moderate sedation as defined by the

137 American Society of Anesthesiologists criteria [8]. Most women remained awake and conversant

138 throughout their procedure and maintained their oxygen saturation in normal range on room air,

139 rarely requiring more than verbal stimulation.

140 An RN administered the sedation and documented all intraoperative monitoring in the

141 electronic medical record (EMR) in real time. Heart rate and pulse oximetry were measured

142 continuously and blood pressure and level of consciousness were recorded every five minutes. 
143 The RN evaluated level of consciousness on a five-point scale (0-no response; 1-responds to pain

144 only; 2-drowsy, hard to arouse, needs tactile stimuli; 3-drowsy, but opens eyes if called several

145 times; 4-drowsy, easily aroused; 5-awake, alert, oriented). RNs did not routinely administer

146 supplemental oxygen, which was generally the first-step intervention for patients unable to

147 maintain oxygen saturation on room air with verbal stimulation alone. The attending physician

148 and sometimes the nurse documented adverse events.

149 We exported data directly from the EMR into a research database. A single investigator

$150(\mathrm{GH})$ individually reviewed the medical records for all procedures coded as having received

151 supplemental oxygen or a reversal agent or resulting in an anesthesia-related adverse event. An

152 attending physician (ABG) additionally reviewed all cases with a possible anesthesia-related

153 adverse event, either identified directly by EMR code or upon review of cases where

154 supplemental oxygen or reversal agents were used.

155 The primary outcome was the use of supplemental oxygen. Secondary outcomes

156 included: use of reversal agents (naloxone or flumazenil), lowest intraoperative level of

157 consciousness (LLOC) recorded, and anesthesia-related adverse events. PPLM considers a

158 LLOC of 0-3 as "low" and considered a potential indicator of over-sedation while a LLOC of 4

159 or 5 is considered normal. We considered the following to be possible anesthesia-related adverse

160 events: aspiration, intubation, asthma attack, vasovagal reaction, seizure, anxiety or psychotic

161 reaction, or any drug reaction. We included vasovagal reactions because they represented a

162 documented, significant change in vital signs from baseline that could have possibly been

163 sedation related. 
165 vaginal deliveries, prior Cesarean deliveries, initial and total fentanyl and midazolam doses, and

166 history of drug use.

167 To determine the baseline rate of supplemental oxygen administration in our population, 168 we performed a clinical audit of a convenience sample of all procedures performed between the 169 introduction of the EMR on September 1, 2010 and the start of this study on June 1, 2015. This 170 revealed a baseline rate of $0.175 \%$. We then calculated that we would need 1,788 procedures to 171 detect an increase in supplemental oxygen administration from $0.175 \%$ to $1 \%, 672$ procedures to 172 detect an increase from $0.175 \%$ to $2 \%$, and 225 procedures to detect an increase from $0.175 \%$ to $1735 \%$ (80\% power, $1.7 \%$ alpha correcting for multiple comparisons). In accordance with the

174 National Institutes of Health BMI classification system, we stratified obese women into three 175 groups and analyzed BMI as a 5-category variable: normal $(\mathrm{BMI}<25)$, overweight $(\mathrm{BMI}=25$ -

176 29.9), obese I $(\mathrm{BMI}=30-34.9)$, obese II $(\mathrm{BMI}=35-39.9)$, and obese III $(\mathrm{BMI} \geq 40)[14]$. We used 177 weight measured in the office and self-reported height to calculate BMI.

178 We compared primary and secondary outcomes between each obesity category and 179 normal weight women. We performed logistic regression for all outcome analyses. We examined 180 pre-selected potential confounders (age, race, ethnicity, gestational age, fentanyl dose,

181 midazolam dose, and street drug use) and included any variables with $p<0.10$ in the univariable

182 analysis in the multivariable model. We used the Wald test to calculate $\mathrm{p}$ values. All statistical 183 analyses were performed using SAS® v 9.4 (Cary, NC).

\section{3. Results}

Between September 1, 2010 and June 1, 2015, PPLM providers performed 23,846 first trimester surgical abortion procedures with moderate IV sedation in 20,573 different patients. 
187 We excluded 3,273 repeat procedures among 2,663 patients and 192 patients for missing BMI,

188 leaving 20,381 patients for our study population. Fifty-four percent of women were normal

189 weight, $26 \%$ were overweight, and $20 \%$ were obese (Table 1). Seven percent (41/550) of obese

190 III women and $0.20 \%(41 / 20,381)$ of the entire study population were super obese with a

191 BMI $\geq 50$ [15]. At PPLM, approximately three-quarters of women undergoing first trimester

192 surgical abortion receive moderate IV sedation. Patients received a median fentanyl dose of 100

193 mcg and median midazolam dose of $2.0 \mathrm{mg}$ (Table 2).

194 The absolute rate of all primary and secondary outcomes was low (Tables 3-4). Thirty-

195 one $(0.15 \%)$ of 20,381 patients required supplemental oxygen (Table 3$)$. In the multivariable

196 analysis for supplemental oxygen, we controlled for fentanyl and midazolam doses and street

197 drug use, and we combined obese II and III women into one group for analysis due to a paucity

198 of outcomes. We found no statistically significant difference in supplemental oxygen

199 administration when comparing obese I and obese II/III women to normal weight women (Obese

200 I versus normal weight, aOR $0.52,95 \%$ CI $0.12-2.27$; obese II/III versus normal weight, aOR

$201 \quad 1.51,95 \%$ CI $0.50-4.54)$.

202 Twenty-four $(0.12 \%)$ of 20,381 patients required a reversal agent, including 19 (79\%)

203 patients with a BMI $<25$ and $23(96 \%)$ with a $\mathrm{BMI}<30$ (Table 3). In the multivariable analysis for

204 reversal agent administration, we controlled for ethnicity and midazolam dose, and we combined

205 obese I, II and III women into one group for analysis due to a paucity of outcomes. We found

206 that the rate of reversal agent administration was lower among obese I, II and III women

207 combined compared to normal weight women (Obese I/II/III versus normal weight, aOR 0.13,

208 95\% CI 0.02-0.96). 
We documented a low LLOC in 184 (0.93\%) of 19,725 patients, including $115(63 \%)$

210 patients with a $\mathrm{BMI}<25$ and $157(85 \%)$ with a $\mathrm{BMI}<30$ (Table 3 ). In the multivariable analysis

211 for low LLOC, we controlled for ethnicity, fentanyl and midazolam doses, and street drug use.

212 There was no significant difference in low LLOC rates between obese I, II or III women and

213 normal weight women (Obese I versus normal weight, aOR 0.65, 95\% CI 0.40-1.06; obese II

214 versus normal weight, aOR $0.54,95 \%$ CI $0.25-1.17$; obese III versus normal weight, aOR 0.14 , $21595 \%$ CI 0.02-1.03).

216 Adverse events determined to be possibly anesthesia-related (0.20\%) included (Table 4):

21732 vasovagal reactions, 3 anxiety reactions, 2 seizures, 1 asthma attack, 1 psychotic reaction, and

2181 other drug reaction. One of these patients $(0.005 \%$ of the total sample) required hospital

219 transfer or hospitalization (for seizure). No patients aspirated or required intubation. Overall, the

220 risk of a non-vasovagal anesthesia-related adverse event was 1 in 2,548 and the risk of

221 hospitalization for an anesthesia-related adverse event was 1 in 20,381.

222 In our multivariable model for all anesthesia-related adverse events, we controlled for

223 age, fentanyl dose, and midazolam dose. There was no significant difference in the frequency of

224 adverse events between any obesity group and normal weight women (Obese I versus normal

225 weight, aOR 1.20, 95\% CI 0.41-3.55; obese II versus normal weight, aOR 0.75, 95\% CI 0.10-

226 5.62; obese III versus normal weight, aOR 3.19, 95\% CI 0.73-13.99). In this model, the risk of

227 anesthesia-related adverse events decreased with increasing dose of both fentanyl and

228 midazolam. This relationship was not observed in the multivariable model for anesthesia-related

229 adverse events when excluding vasovagal reactions. Of the 8 (0.04\%), non-vasovagal,

230 anesthesia-related adverse events included in this analysis, none occurred in women with a BMI

231 of 35 or greater (Table 4). Given the rarity of these adverse events, obese I, II and III were 
232 combined for analysis. In our multivariable model controlling for ethnicity, there was no

233 relationship between BMI and the occurrence of anesthesia-related adverse events excluding

234 vasovagal reactions (obese I/II/III versus normal weight, aOR $0.59,95 \%$ CI $0.07-5.31$ ).

\section{4. Discussion}

236 We sought to determine if obese I, II and III women experienced increased adverse

237 outcomes with moderate IV sedation during first trimester surgical abortion compared to normal

238 weight women. Among patients undergoing a first trimester surgical abortion with moderate IV

239 sedation, we found no difference in the rate of supplemental oxygen administration or in the rate

240 of low intraoperative LLOC when comparing each obesity group and normal weight women.

241 Additionally, we found that obese women required reversal agent administration at a

242 significantly lower rate than normal weight women.

243 We found that the absolute rate of any anesthesia-related adverse events was exceedingly

244 low across all BMI categories and the rate of serious adverse outcomes resulting in hospital

245 transfer or hospitalization was even lower. Additionally, over three-quarters of anesthesia-related

246 adverse events were self-limited vasovagal reactions, and may represent inadequate pain control

247 given the inverse relationship with sedation dosing and/or may be related to the paracervical

248 block, rather than over-sedation.

249 A strength of this study is its large sample size, which allows detection of small increases

250 in adverse outcomes. We chose a primary outcome of oxygen administration to maximize

251 sensitivity for detecting any possible anesthesia-related adverse events. We designated this

252 surrogate marker as our primary outcome because in our setting oxygen is not routinely used, is

253 reliably recorded, and is usually the first step in management of hypo-oxygenation that does not

254 respond to verbal or tactile stimulation. This sensitive measure coupled with the large sample 
255 size leaves us confident that we detected all adverse events in our population and that there is no 256 clinically relevant association between supplemental oxygen use and BMI.

257 The retrospective nature of the data limited this study. We were limited to the data fields

258 and procedures collected after the EMR was adopted in 2010. The template utilized for

259 documenting abortion procedures at PPLM largely consisted of check boxes and drop-down

260 menus, which standardizes documentation and minimizes the amount of missing data.

261 Intraoperative pain scores were unreliably documented in EMR, so we could not assess whether

262 sedation at the doses administered adequately controlled pain. It is possible that since most

263 women received the same doses of fentanyl and midazolam, normal and underweight women

264 may be receiving doses of sedation that are too high or obese women receiving doses that are too

265 low, possibly resulting in the lower rates of complications and less effective pain control among

266 obese women. Unfortunately we did not export data on asthma from the EMR at the time of

267 database creation, which could have been a confounder. Different providers may also have had

268 different thresholds for utilizing supplemental oxygen or reversal agents, so use of these

269 interventions as a marker for over-sedation may represent varying levels of over-sedation and

270 concern. However, we believe these outcomes consistently capture any serious anesthesia-related

271 adverse events or cases of over-sedation and likely over-diagnose adverse events.

272 Only $20 \%$ of our study population was obese compared to roughly one-third of

273 reproductive aged women in the United States. While our study population was thinner than the

274 population of reproductive aged women in the United States, our study had a prevalence of

275 obesity similar to that of Massachusetts [16]. Additionally, we had a limited number of women

276 with a $\mathrm{BMI} \geq 50$ and physicians thoroughly screened for serious medical co-morbidities. We are

277 fortunate in Massachusetts that most state residents can access a hospital-based abortion when 
278 required. Thus our results may not be generalizable to the super obese population, to women

279 with serious medical co-morbidities, and to those in settings with limited access to hospital-based

280 care where patients may conceal medical co-morbidities in order to access abortion services [15].

281 Investigation into the safety of moderate IV sedation among obese women is limited. A

282 retrospective review of 143,000 procedures performed with fentanyl and midazolam outside of

283 the operating room at a tertiary care medical center found that BMI, age, co-morbidities, and

284 type of procedure (gastroenterology and cardiology) were independently associated with adverse

285 events [17]. This patient population was markedly older, with a mean age of 59.2 years, and had

286 more co-morbidities than patients typically seen in freestanding abortion clinics. These were also

287 typically longer procedures with ongoing titration of medication, and it is unclear if these results

288 are generalizable to young, generally healthy obese people who undergo short procedures.

289 Another study of second trimester surgical abortion up until 24 0/7 weeks gestation

290 demonstrated that obese women required increased anesthesia and operative times, but there was

291 no significant difference in overall complication rates compared to non-obese women [18].

292 However, this study evaluated procedures performed in a hospital operating room with general

293 anesthesia and had limited power to evaluate anesthesia-specific events. A recent study

294 evaluating anesthesia complications among 5,579 obese and non-obese women undergoing first

295 and second trimester abortion utilizing fentanyl, midazolam, and propofol without intubation in a

296 freestanding clinic reported no serious adverse outcomes in either group and concluded that

297 based on the upper $95 \%$ confidence interval for their sample size, the maximal risk of a serious

298 anesthesia-related complication was 1 in 1,860 procedures [19].

299 Our study suggests that with appropriate clinical screening and judgment, an RN in

300 conjunction with an operating physician can safely administer IV sedation to obese women 
301 seeking first trimester surgical abortion in an outpatient clinical setting and that restrictions based

302 on BMI alone are unnecessary. While some women denied moderate IV sedation in an outpatient

303 clinical setting might have their procedure with local anesthesia alone, others would require

304 hospital referral, which could lead to delays in care or no care at all in places with very limited

305 access and prohibitive cost [20,21]. Increased physician comfort with the provision of moderate

306 IV sedation in obese women and elimination of restrictions on moderate IV sedation could

307 improve access to abortion for a large segment of the abortion seeking population. 


\section{References}

309 [1] Jones RK, Jerman J. Abortion incidence and service availability in the United States, 2014.

310 Perspect Sex Reprod Health 2017;49(1):17-27.

311 [2] Guttmacher Institute. Induced abortion in the United States.

312 https://www.guttmacher.org/sites/default/files/factsheet/fb_induced_abortion_5.pdf; 2017

313 [accessed 08.19.17].

314 [3] Henshaw SK. Unintended pregnancy in the United States. Fam Plann Perspect

$3151998 ; 30(1): 24-9,46$.

316 [4] Jones RK, Kavanaugh ML. Changes in abortion rates between 2000 and 2008 and lifetime

317 incidence of abortion. Obstet Gynecol 2011;117(6):1358-66.

318 [5] Flegal KM, Carroll MD, Kit BK, Ogden CL. Prevalence of obesity and trends in the

319 distribution of body mass index among US adults, 1999-2010. JAMA 2012;307(5):491-7.

320 [6] O’Connell K, Jones HE, Simon M, Saporta V, Paul M, Lichtenberg ES. First-trimester

321 surgical abortion practices: a survey of National Abortion Federation members. Contraception $322 \quad 2009 ; 79(5): 385-92$.

323 [7] O’Connell K, Jones HE, Lichtenberg ES, Paul M. Second-trimester surgical abortion 324 practices: a survey of National Abortion Federation members. Contraception 2008;78(6):492-9.

325 [8] American Society of Anesthesiologists. Continuum of depth of sedation: definition of general 326 anesthesia and levels of sedation/analgesia.

327 http://www.asahq.org/ /media/sites/asahq/files/public/resources/standards-

328 guidelines/continuum-of-depth-of-sedation-definition-of-general-anesthesia-and-levels-of-

329 sedation-analgesia.pdf; 2014 [accessed 07.20.17]. 
330 [9] Wong CY, Ng EH, Ngai SW, Ho PC. A randomized, double blind, placebo-controlled study

331 to investigate the use of conscious sedation in conjunction with paracervical block for reducing

332 pain in termination of first trimester pregnancy by suction evacuation. Hum Reprod

$3332002 ; 17(5): 1222-5$.

334 [10] Rawling MJ, Wiebe ER. A randomized controlled trial of fentanyl for abortion pain. Am J

335 Obstet Gynecol 2001;185(1):103-7.

336 [11] Allen RH, Kumar D, Fitzmaurice G, Lifford KL, Goldberg AB. Pain management of first-

337 trimester surgical abortion: effects of selection of local anesthesia with and without lorazepam or

338 intravenous sedation. Contraception 2006;74(5):407-13.

339 [12] Allen RH, Fitzmaurice G, Lifford KL, Lasic M, Goldberg AB. Oral compared with

340 intravenous sedation for first-trimester surgical abortion. Obstet Gynecol 2009;113(2):276-83.

341 [13] Allen RH, Fortin J, Bartz D, Goldberg AB, Clark MA. Women's preferences for pain

342 control during first-trimester surgical abortion: a qualitative study. Contraception

$343 \quad 2012 ; 85(4): 413-8$.

344 [14] National Institutes of Health. Classification of overweight and obesity by BMI, waist

345 circumference, and associated disease risks.

346 https://www.nhlbi.nih.gov/health/educational/lose_wt/BMI/bmi_dis.htm [accessed 07.20.17].

347 [15] Strum R. Increases in morbid obesity in the USA: 2000-2005. Public Health

$348 \quad 2007 ; 121(7): 492-6$.

349 [16] Segal LM, Martín A, Rayburn J. The state of obesity: better policies for a healthier America.

350 http://stateofobesity.org/files/stateofobesity2016.pdf; 2016 [accessed 07.20.17]. 
351 [17] Karamnov S, Sarkisian N, Grammer R, Gross WL, Urman RD. Analysis of adverse events 352 associated with adult moderate procedural sedation outside the operating room. J Patient Saf 353 2014;[Epub ahead of print].

354 [18] Murphy LA, Thornburg LL, Glantz JC, Wasserman EC, Stanwood NL, Betstadt SJ.

355 Complications of surgical termination of second-trimester pregnancy in obese versus nonobese

356 women. Contraception 2012;86(4):402-6.

357 [19] Gokhale P, Lappen JR, Waters JH, Perriera LK. Intravenous sedation without intubation and

358 the risk of anesthesia complications for obese and non-obese women undergoing surgical

359 abortion: A retrospective cohort study. Anesth Analg 2016;122(6):1957-62.

360 [20] Bartlett LA, Berg CJ, Shulman HB, Zane SB, Green CA, Whitehead S, Atrash HK. Risk

361 factors for legal induced abortion-related mortality in the United States. Obstet Gynecol 2004;

362 103(4):729-37.

363 [21] Rausch M, Lorch S, Chung K, Frederick M, Zhang J, Barnhart K. A cost-effectiveness

364 analysis of surgical versus medical management of early pregnancy loss. Fertil Steril 2012;

365 97(2):355-60.

366 
367 Table 1: Baseline characteristics of women undergoing first trimester surgical abortion with 368 moderate intravenous sedation by BMI category $(\mathrm{N}=20,381)$

369

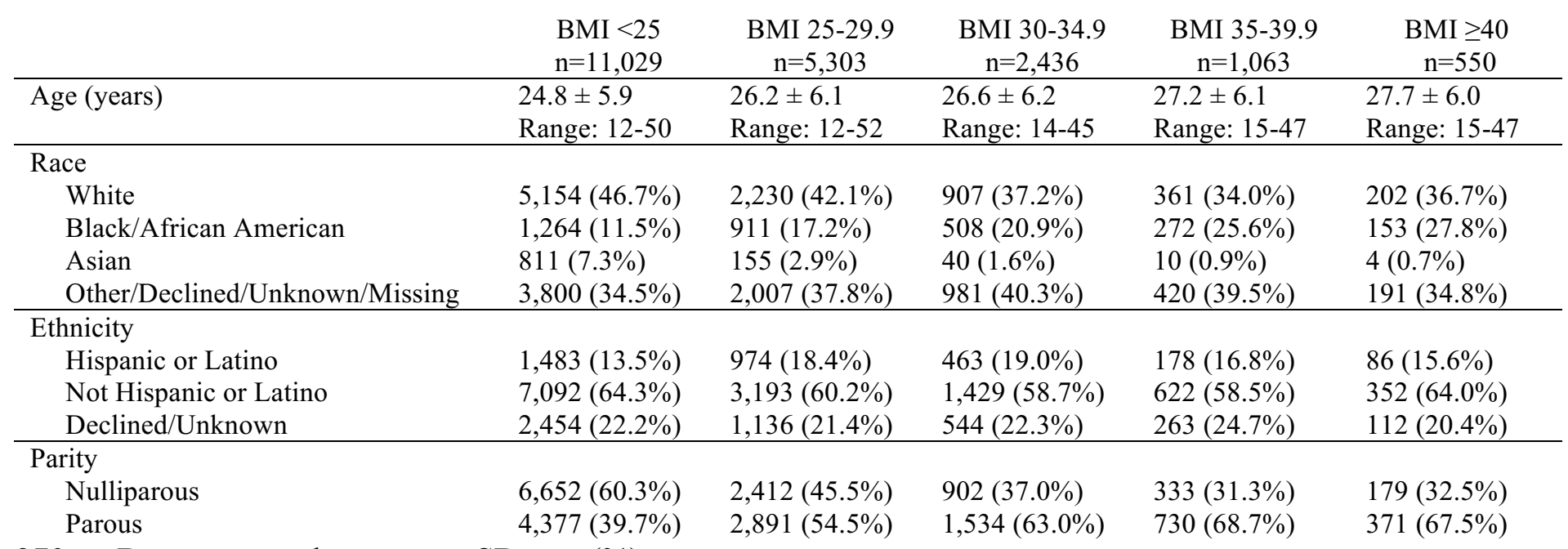

370 Data presented as mean $\pm \mathrm{SD}$ or $\mathrm{n}(\%)$. 
371 Table 2: Fentanyl and midazolam dosing for moderate intravenous sedation during first trimester 372 surgical abortion by BMI category $(\mathrm{N}=20,381)$

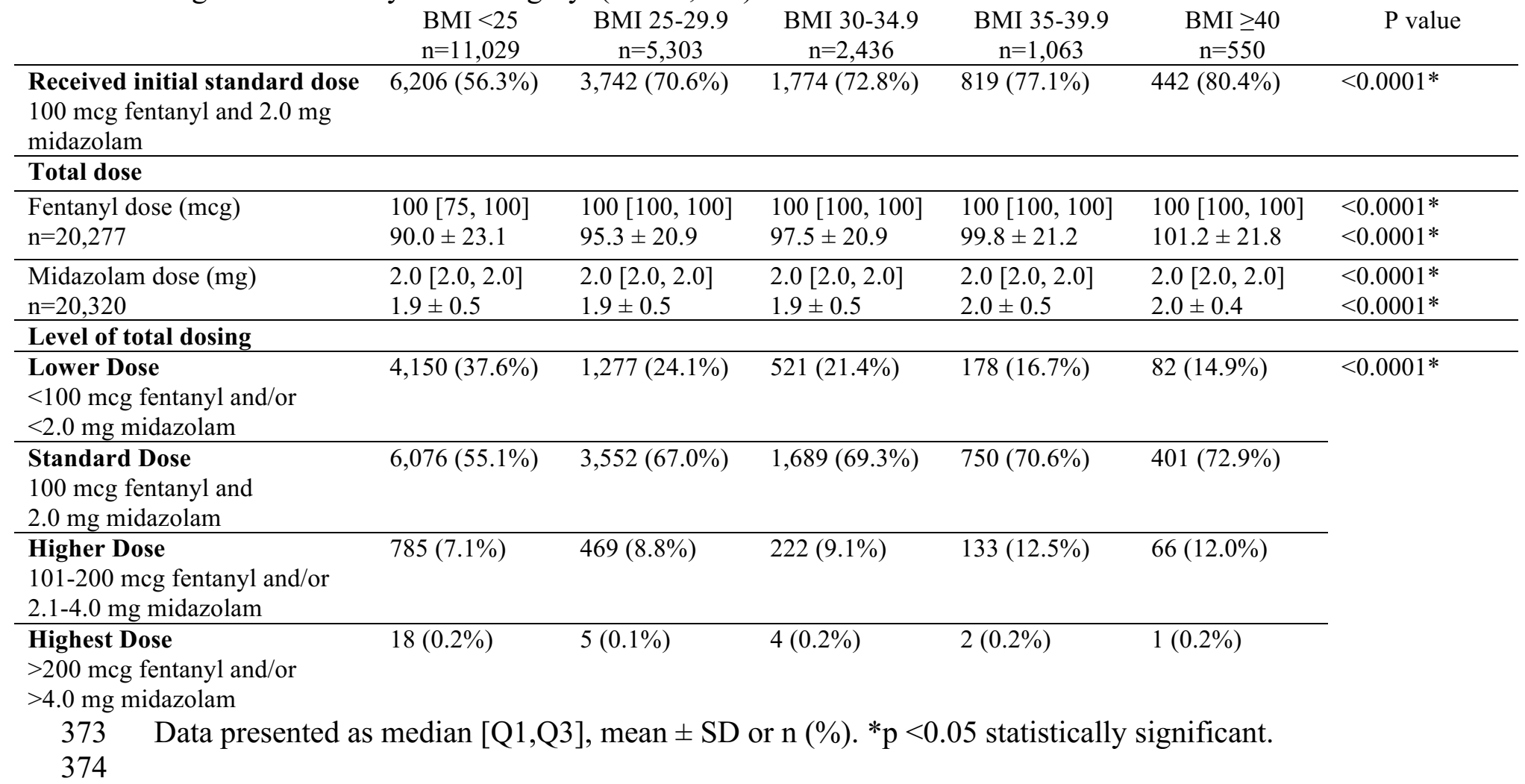


375 Table 3: Markers of over-sedation by BMI during first trimester surgical abortion with moderate 376 intravenous sedation

\begin{tabular}{|c|c|c|c|c|c|c|}
\hline & $\begin{array}{c}\text { BMI }<25 \\
\text { Normal } \\
\text { weight }\end{array}$ & $\begin{array}{c}\text { BMI 25-29.9 } \\
\text { Overweight }\end{array}$ & $\begin{array}{c}\text { BMI } 30-34.9 \\
\text { Obese I }\end{array}$ & $\begin{array}{c}\text { BMI } 35-39.9 \\
\text { Obese II }\end{array}$ & $\begin{array}{l}\text { BMI } \geq 40 \\
\text { Obese III }\end{array}$ & $\mathrm{P}$ value \\
\hline $\begin{array}{l}\text { Received supplemental } \\
\text { oxygen }\end{array}$ & $\begin{array}{c}16 / 11,029 \\
(0.15 \%)\end{array}$ & $\begin{array}{l}9 / 5,303 \\
(0.17 \%)\end{array}$ & $\begin{array}{l}2 / 2,436 \\
(0.08 \%)\end{array}$ & $\begin{array}{l}4 / 1,063 \\
(0.38 \%)\end{array}$ & $0 / 550$ & 0.61 \\
\hline $\begin{array}{l}\text { Received reversal } \\
\text { agent }\end{array}$ & $\begin{array}{c}19 / 11,029 \\
(0.17 \%) \\
\end{array}$ & $\begin{array}{l}4 / 5,303 \\
(0.08 \%) \\
\end{array}$ & $\begin{array}{l}1 / 2,436 \\
(0.04 \%) \\
\end{array}$ & $0 / 1,063$ & $0 / 550$ & 0.07 \\
\hline $\begin{array}{l}\text { Documented low } \\
\text { lowest level of } \\
\text { consciousness }\end{array}$ & $\begin{array}{c}115 / 10,716 \\
(1.07 \%)\end{array}$ & $\begin{array}{c}42 / 5,116 \\
(0.82 \%)\end{array}$ & $\begin{array}{c}19 / 2,343 \\
(0.81 \%)\end{array}$ & $\begin{array}{l}7 / 1,027 \\
(0.68 \%)\end{array}$ & $\begin{array}{c}1 / 522 \\
(0.19 \%)\end{array}$ & 0.17 \\
\hline
\end{tabular}

377 Data are presented as $\mathrm{n}(\%) . \mathrm{p}<0.05$ statistically significant. Level of consciousness measured on 378 a five-point scale (0-no response; 1-responds to pain only; 2-drowsy, hard to arouse, needs tactile 379 stimuli; 3-drowsy, but opens eyes if called several times; 4-drowsy, easily aroused; 5-awake, 380 alert, oriented) and score of 0-3 considered "low" and a potential indicator of over-sedation. 
381 Table 4: Rate of anesthesia-related adverse events by BMI during first trimester surgical abortion 382 with moderate intravenous sedation $(\mathrm{N}=20,381)$

\begin{tabular}{ccccccc} 
& $\begin{array}{c}\text { BMI }<25 \\
\text { Normal } \\
\text { weight } \\
\mathrm{n}=11,029\end{array}$ & $\begin{array}{c}\text { BMI 25-29.9 } \\
\text { Overweight } \\
\mathrm{n}=5,303\end{array}$ & $\begin{array}{c}\text { BMI 30-34.9 } \\
\text { Obese I } \\
\mathrm{n}=2,436\end{array}$ & $\begin{array}{c}\text { BMI 35-39.9 } \\
\text { Obese II } \\
\mathrm{n}=1,063\end{array}$ & $\begin{array}{c}\text { BMI } \geq 40 \\
\text { Obese III } \\
\mathrm{n}=550\end{array}$ & P value \\
\hline $\begin{array}{c}\text { Any anesthesia-related } \\
\text { adverse event }\end{array}$ & $\begin{array}{c}21 \\
(0.19 \%)\end{array}$ & $\begin{array}{c}12 \\
(0.23 \%)\end{array}$ & $\begin{array}{c}4 \\
(0.16 \%)\end{array}$ & $\begin{array}{c}1 \\
(0.09 \%)\end{array}$ & $\begin{array}{c}2 \\
(0.36 \%)\end{array}$ & 0.80 \\
\hline $\begin{array}{c}\text { Anesthesia-related } \\
\text { events excluding } \\
\text { vasovagal reactions }\end{array}$ & $\begin{array}{c}4 \\
(0.04 \%)\end{array}$ & $\begin{array}{c}3 \\
(0.06 \%)\end{array}$ & $\begin{array}{c}1 \\
(0.04 \%)\end{array}$ & 0 & 0 & 0.73 \\
\hline $\begin{array}{c}\text { Anesthesia-related } \\
\text { hospitalization }\end{array}$ & $\begin{array}{c}1 \\
(0.01 \%)\end{array}$ & 0 & 0 & 0 & 0 & N/A
\end{tabular}

383 Data are presented as $\mathrm{n}(\%) . \mathrm{p}<0.05$ statistically significant. All anesthesia-related adverse

384 events included: vasovagal reaction, anxiety reaction, seizure, asthma attack, psychotic reaction, 385 and drug reaction. Hospitalization for seizure. 